\title{
Thermodynamic Studies of Zippeite, a Uranyl Sulfate Common in Mine Wastes
}

\author{
Melika Sharifironizi ${ }^{\mathrm{a}}$, Jennifer E.S. Szymanowski ${ }^{\mathrm{a}}$, Ginger E. Sigmon ${ }^{\mathrm{a}}$, Alexandra Navrotsky ${ }^{\mathrm{b}}$
} Jeremy B. Fein ${ }^{\mathrm{a}}$, Peter C. Burns ${ }^{\mathrm{a}, \mathrm{c}, 1}$

${ }^{a}$ Department of Civil and Environmental Engineering and Earth Sciences, University of Notre Dame, Notre Dame, IN 46556; ${ }^{b}$ Peter A. Rock Thermochemistry Laboratory and Nanomaterials in the Environment, Agriculture, and Technology Organized Research Unit, University of California, Davis, CA 95616; ${ }^{\circ}$ Department of Chemistry and Biochemistry, University of Notre Dame, Notre Dame, IN 46556

${ }^{1}$ To whom correspondence should be addressed. Email: pburns@nd.edu

\begin{abstract}
:
Zippeite is a potassium uranyl sulfate mineral that forms on uranium mine wastes and that may be important in nuclear waste disposal. Little is known about its thermodynamic properties. In this study, we synthesized zippeite, $\mathrm{K}_{3}\left(\mathrm{H}_{2} \mathrm{O}\right)\left[\left(\mathrm{UO}_{2}\right)_{4}\left(\mathrm{SO}_{4}\right)_{2} \mathrm{O}_{3}(\mathrm{OH})\right]$, and measured its thermodynamic properties. The standard enthalpy of formation of zippeite from the elements, $8655.97 \pm 12.55 \mathrm{~kJ} / \mathrm{mol}$, was calculated from the measured enthalpy of dissolution in a hightemperature oxide melt solution calorimeter. Solubility measurements were conducted from both undersaturation and supersaturation in order to constrain the equilibrium state. Using the solubility product $\left(\mathrm{K}_{\mathrm{sp}}\right)$ obtained from the solubility data, the standard Gibbs free energy of formation of zippeite at $297 \mathrm{~K}$ was calculated to be $-7783.44 \pm 6.87 \mathrm{~kJ} / \mathrm{mol}$. This value, coupled with the standard enthalpy of formation value determined from the calorimetric data, was then used to calculate the standard entropy of formation, $-2926.49 \pm 45.64 \mathrm{~J} / \mathrm{mol}$. Our studies yield the first complete set of thermodynamic properties of zippeite, and the results allow us to predict the conditions under which its formation is favorable relative to other uranyl minerals under a wide range of conditions of geologic and engineering interest.
\end{abstract}

Keywords: Zippeite, Uranyl sulfate, Uranium mine waste, Calorimetry, Solubility, Enthalpy, Entropy, Gibbs free energy

\section{Introduction}

Zippeite, $\mathrm{K}_{3}\left(\mathrm{H}_{2} \mathrm{O}\right)_{3}\left[\left(\mathrm{UO}_{2}\right)_{4}\left(\mathrm{SO}_{4}\right)_{2} \mathrm{O}_{3}(\mathrm{OH})\right]$, is a relatively soluble mineral that generally forms under low $\mathrm{pH}$ conditions during and subsequent to the alteration of uraninite, $\mathrm{UO}_{2+\mathrm{x}}$, and 
sulfide minerals, such as pyrite and galena, under oxidizing conditions (Brugger et al., 2003; Frondel et al., 1976; Plášil et al., 2014c). The aqueous solubility of uranium minerals is important in determining the distribution and transport of uranium under oxidizing conditions. Uranyl sulfates significantly impact the mobility of uranium in water, especially in former uranium mines and related mine tailings (Finch and Murakami, 1999). Zippeite is particularly important in abandoned uranium mines that discharge acid drainage due to sulfide oxidation. It is common in abandoned uranium mining sites where sulfuric acid leaching was used to recover uranium (Meinrath et al., 2006; Plášil et al., 2014a; Plášil et al., 2011a; Plášil et al., 2013; Plášil et al., 2014b; Plášil et al., 2011b). In addition to these occurrences in the environment, uranyl sulfates like zippeite may form in the stainless steel canisters intended to house spent nuclear fuel in a nuclear repository, as several studies have shown that manganese sulfide inclusions in stainless steel are susceptible to corrosion (Ryan et al., 2002; Williams and Zhu, 2000). Under oxidizing conditions, such as in the previously proposed repository at Yucca Mountain NV, sulfide inclusions that are initiation sites for pitting may convert to sulfate, and uranyl sulfates may affect the overall concentration and transport of uranium in a repository setting (Merkel et al., 2002). The presence of sulfate in Hanford tank wastes arising from the bismuth phosphate process used during nuclear weapons production adds to the need to understand the thermodynamic properties of zippeite (Tingey et al., 2004).

There currently is a lack of reliable thermodynamic data for zippeite. To date, there has been only one report concerning the Gibbs free energy of zippeite (O'Brien and Williams, 1981), with a value derived from dissolution studies and metal aqueous complexation calculations.

O'Brien and Williams reported the Gibbs free energy of formation of zippeite from the elements to be $-12603 \pm 10 \mathrm{~kJ} / \mathrm{mol}$ (O'Brien and Williams, 1981). In that study, it was not clear that equilibrium was attained during the experiment, the enthalpy and entropy of formation were not determined, the composition of the zippeite studied was uncertain (see below), and the possibility of non-stochiometric (incongruent) dissolution was not evaluated by analyzing the residual solid phase after the experiments. Prediction of the Gibbs free energy and enthalpy of formation of various $\mathrm{U}^{6+}$ phases, including K-zippeite, has been conducted based on models involving the polyhedral geometries and coordination numbers of the cations involved (Chen et al., 1999). 
Subsequent to the earlier studies, Burns et al. characterized crystals of synthetic material and defined the structure and formula of zippeite, $\mathrm{K}_{3}\left(\mathrm{H}_{2} \mathrm{O}\right)_{3}\left[\left(\mathrm{UO}_{2}\right)_{4}\left(\mathrm{SO}_{4}\right)_{2} \mathrm{O}_{3}(\mathrm{OH})\right]$ (Burns et al., 2003), both of which differ from the results from the earlier studies. The zippeite structure contains sheets of uranyl pentagonal bypiramids and sulfate tetrahedra (Burns et al., 2003)(Figure S1). Each bipyramid shares two of its equatorial edges with two other uranyl bipyramids, forming a zig-zag chain that is two bipyramids wide. These chains are connected to each other through four-connected sulfate tetrahedra to form sheets. The uranyl sulfate sheets are linked through bonds to potassium cations, as well as through hydrogen bonds associated with water groups. Using a bond valence approach and the electro neutrally requirement, Burns et al. showed that previous formulas and structures were based on natural zippeite with impurities or were not accurate (Burns et al., 2003).

In this work, we have synthesized zippeite and confirmed the purity of the phase using powder X-ray diffraction (PXRD), inductively coupled plasma optical emission spectroscopy (ICP-OES), and thermogravimetric analysis (TGA). We conducted solubility studies both from undersaturation and oversaturation, as well as high temperature oxide melt solution calorimetry in order to determine the thermodynamic properties of zippeite, and we use these results to illustrate the calculation of the thermodynamic stability of zippeite relative to other uranylbearing phases under a range of conditions.

\section{Materials and Methods}

Caution: Although the uranium used in the experiments described here was isotopically depleted, precautions for handling radioactive materials should be followed. In our experiments, all of the reagents, unless otherwise stated, were analytical grade and used as received without further purification. Zippeite was synthesized hydrothermally by combining $0.254 \mathrm{~g}$ uranyl acetate, $0.052 \mathrm{~g}$ potassium sulfate, and $4 \mathrm{~mL}$ ultrapure $18 \mathrm{M} \Omega \mathrm{H}_{2} \mathrm{O}$ in a $23 \mathrm{~mL}$ Teflon-lined Parr reaction vessel. The $\mathrm{pH}$ of the solution was adjusted to $4.3 \mathrm{using} 1 \mathrm{M} \mathrm{KOH}$. Several batches of material were made and mixed together in order to accumulate enough material for characterization, calorimetric studies and solubility measurements. The reaction vessel was placed inside a mechanical convection oven and heated to $150{ }^{\circ} \mathrm{C}$. After 3 days, the reaction vessel was removed from the oven and allowed to cool to ambient temperature. The yellow micro-crystalline zippeite was recovered by air-filtration and washed with ultrapure 
water. To verify the purity, powder X-ray diffraction (PXRD) patterns were collected using a Bruker D8 Davinci diffractometer equipped with monochromatic $\mathrm{Cu} \mathrm{K} \alpha$-radiation over the $2 \theta$ range from 5 to 55 with a step size and exposure time of $0.01^{\circ}$ and $1 \mathrm{~s}$, respectively.

The elemental composition of the synthesized zippeite was determined by complete dissolution of the synthesized material followed by elemental analysis using a Perkin Elmer Optima 8000 DV-ICP-OES instrument. Approximately $0.12 \mathrm{mg}$ of the sample was dissolved in $10 \mathrm{~mL}$ diluted $(5 \%) \mathrm{HNO}_{3}$ and analyzed in triplicate for the concentrations of $\mathrm{U}, \mathrm{S}$, and $\mathrm{K}$ in solution. Six external standards having the elements of interest with concentration ranging from 0.1 to $20 \mathrm{ppm}$ were used for calibration. Also, yttrium was added to all samples and standards at a concentration of $0.6 \mathrm{ppm}$ to monitor instrument drift. The experimental ratios between the elements of interest, $\mathrm{U}, \mathrm{K}$, and $\mathrm{S}$ were in good agreement with the chemical formula associated with the crystalline phase of zippeite (Burns et al., 2003).

Thermogravimetric and differential scanning calorimetric analyses were carried out using a Mettler Toledo TGA/DSC with a vertical balance calibrated by alumina pellets coupled with a mass spectrometer (Thermo Star, Pfeiffer) for evolved gas analysis. The number of molecules of water associated with the synthetic phase was calculated based on mass change upon temperature increase. A $25 \mathrm{mg}$ pellet of the sample was heated up to $950{ }^{\circ} \mathrm{C}$ at a $5{ }^{\circ} \mathrm{C} / \mathrm{min}$ heating rate under flowing Ar gas at $50 \mathrm{~mL} / \mathrm{min}$.

A high temperature twin Calvet calorimeter, model AlexSYS 1000 produced by Setaram, was used to measure the enthalpy of dissolution of zippeite in the melt $\left(3 \mathrm{Na}_{2} \mathrm{O}-4 \mathrm{MoO}_{3}\right)$ at 700 ${ }^{\circ} \mathrm{C}$. It has been shown that this method gives reliable data for the enthalpy of dissolution of uranyl compounds (Navrotsky, 1977; Navrotsky, 1997). Based on the drop solution enthalpy, the enthalpies of formation of the sample from its elements and binary oxides were calculated using thermochemical cycles. The instrument was calibrated using the heat content of high purity $\alpha$ $\mathrm{Al}_{2} \mathrm{O}_{3}$. The complete dissolution of the zippeite in $3 \mathrm{Na}_{2} \mathrm{O}_{3}-4 \mathrm{MoO}_{3}$ was confirmed by experiments in a furnace at $700{ }^{\circ} \mathrm{C}$ and visual inspection, where $\sim 5 \mathrm{mg}$ of zippeite was dropped into the molten solvent and a clear solution was observed after about $25 \mathrm{~min} . \mathrm{O}_{2}$ gas was used as the flushing gas over the solvent at a constant rate, $35 \mathrm{~mL} / \mathrm{min}$, to evolve any gas or water vapors associated with dissolution. $\mathrm{O}_{2}$ was also the bubbling gas and was bubbled at $5 \mathrm{~mL} / \mathrm{min}$ through the solvent to provide stirring as well as an oxidizing environment and to prevent local saturation in the solvent. 
Raman spectroscopy was conducted using a Bruker Sentinel system linked via fiber optics to a video-assisted Raman probe equipped with a $785 \mathrm{~nm}, 400 \mathrm{~mW}$ light source, TE-cooled, $1024 * 255$ CCD array. The spectra were collected over a frequency range of $\sim 300-2500 \mathrm{~cm}^{-1}$ for 15 seconds with 3 integrations and a 45 second background. Raman spectra of the starting material, zippeite, were compared with the Raman spectra of the residue of the solubility experiments.

Solubility experiments were conducted approaching equilibrium from both under- and super-saturation. To approach equilibrium from undersaturation, approximately $500 \mathrm{mg}$ of the synthesized zippeite sample was added to $8 \mathrm{~mL}$ of $0.1 \mathrm{M} \mathrm{NaClO}_{4}$ in a reaction vessel. The $\mathrm{pH}$ of the solution was kept below 4 using diluted $\mathrm{HCl}$ to simplify the aqueous speciation of uranium and to ensure that aqueous uranyl carbonate and uranyl hydroxide complexes are not dominant species in the experimental solution (Choppin and Mathur, 1991; Tripathi, 1983). Solubility measurements from under-saturation were conducted at three different $\mathrm{pH}$ values, 2.8, 3.5 and 4. A solubility experiment that approached equilibrium from supersaturation was conducted at $\mathrm{pH}$ 3.5 by addition of $\sim 500 \mathrm{mg}$ zippeite to $8 \mathrm{~mL}$ of $0.1 \mathrm{M} \mathrm{NaClO}_{4}$ solution that already contained dissolved $\mathrm{U}, \mathrm{K}$, and $\mathrm{S}$ from the addition of $\mathrm{UO}_{2}\left(\mathrm{NO}_{3}\right)_{2}$ and $\mathrm{K}_{2} \mathrm{SO}_{4}$. The starting concentrations of $\mathrm{U}, \mathrm{K}$, and $\mathrm{S}$ were $0.044,0.05$, and $0.026 \mathrm{~mol} / \mathrm{L}$, respectively, and were identical to those measured for the undersaturation experiment at $\mathrm{pH} 3.5$. All experiments were conducted in Teflon reaction vessels, which were sealed and the $\mathrm{pH}$ of each solution was measured and adjusted each day for four weeks using a $\mathrm{pH}$ meter calibrated by 3 NIST standards. At various intervals, aliquots of solution were taken from each tube and filtered with $0.1 \mu \mathrm{L}$ nylon filters, to remove any residual solid. Subsequently, the solution samples were diluted in about $10 \mathrm{~mL}$ of diluted $(5 \%) \mathrm{HNO}_{3}$ acid for ICP-OES analyses to measure the concentration of the elements of interest. At the end of each experiment, about $20 \mathrm{mg}$ of the remaining powder was used for PXRD and ICP-OES analysis in order to test whether the solid phase was stable over the duration of the experiment and that the composition of the remaining solid did not change.

\section{Results and Discussion}

The PXRD pattern of finely ground synthetic zippeite deposited onto a zero-background quartz plate is shown in Figure S2. The observed pattern is in good agreement with that 
calculated from the previously published zippeite structure model by Burns et al. (Burns et al., 2003) and there are no additional peaks. Chemical analysis results are in good agreement with the accepted formula (Table S1). Thermogravimetric analysis (Figure S3) yielded a somewhat higher water content than expected (3.3 moles of water instead of 3), likely due to surface water that was lost at $40-80^{\circ} \mathrm{C}$. Loss of structural water occurred at $80-150{ }^{\circ} \mathrm{C}$. During heating to 650 $900{ }^{\circ} \mathrm{C}, \mathrm{SO}_{2}$ was liberated from the sample, as confirmed by mass spectrometry of the evolved gas.

High temperature oxide melt solution calorimetry using molten sodium molybdate at 700 ${ }^{\circ} \mathrm{C}$ was used to determine the standard enthalpy of formation of zippeite using a well-established methodology (Navrotsky, 1997; Navrotsky, 2014). The sample readily dissolved in the melt and the calorimetric reaction was complete after about 33 minutes, as indicated by the calorimeter signal returning to the original baseline. Using thermochemical cycles (Table 1) the enthalpy of formation of zippeite from its binary oxides and elements was calculated to be $-1338.53 \pm 11.74$ $\mathrm{kJ} / \mathrm{mol}$ and $-8655.97 \pm 12.55 \mathrm{~kJ} / \mathrm{mol}$, respectively. Reactions 1 and 2 represent zippeite formation from its oxides and elements:

$$
\begin{aligned}
& 1.5 \mathrm{~K}_{2} \mathrm{O}_{(\mathrm{xl}, 298 \mathrm{~K})}+4 \mathrm{UO}_{3(\mathrm{xl}, 298 \mathrm{~K})}+2 \mathrm{SO}_{3(\mathrm{~g}, 298 \mathrm{~K})}+3.8 \mathrm{H}_{2} \mathrm{O}_{(\mathrm{l}, 298 \mathrm{~K})}= \\
& \mathrm{K}_{3}\left(\mathrm{H}_{2} \mathrm{O}\right)_{3.3}\left[\left(\mathrm{UO}_{2}\right)_{4}\left(\mathrm{SO}_{4}\right)_{2} \mathrm{O}_{3}(\mathrm{OH})\right]_{(\mathrm{xl}, 298 \mathrm{~K})} \\
& 3 \mathrm{~K}_{(\mathrm{xl}, 298 \mathrm{~K})}+4 \mathrm{U}_{(\mathrm{xl}, 298 \mathrm{~K})}+2 \mathrm{~S}_{(\mathrm{s}, 298 \mathrm{~K})}+3.8 \mathrm{H}_{2(\mathrm{~g}, 298 \mathrm{~K})}+11.65 \mathrm{O}_{2}(\mathrm{~g}, 298 \mathrm{~K})= \\
& \mathrm{K}_{3}\left(\mathrm{H}_{2} \mathrm{O}\right)_{3.3}\left[\left(\mathrm{UO}_{2}\right)_{4}\left(\mathrm{SO}_{4}\right)_{2} \mathrm{O}_{3}(\mathrm{OH})\right]_{(\mathrm{xl}, 298 \mathrm{~K})}
\end{aligned}
$$

Table1. Thermodynamic cycles for formation of zippeite from its elements and binary oxides.

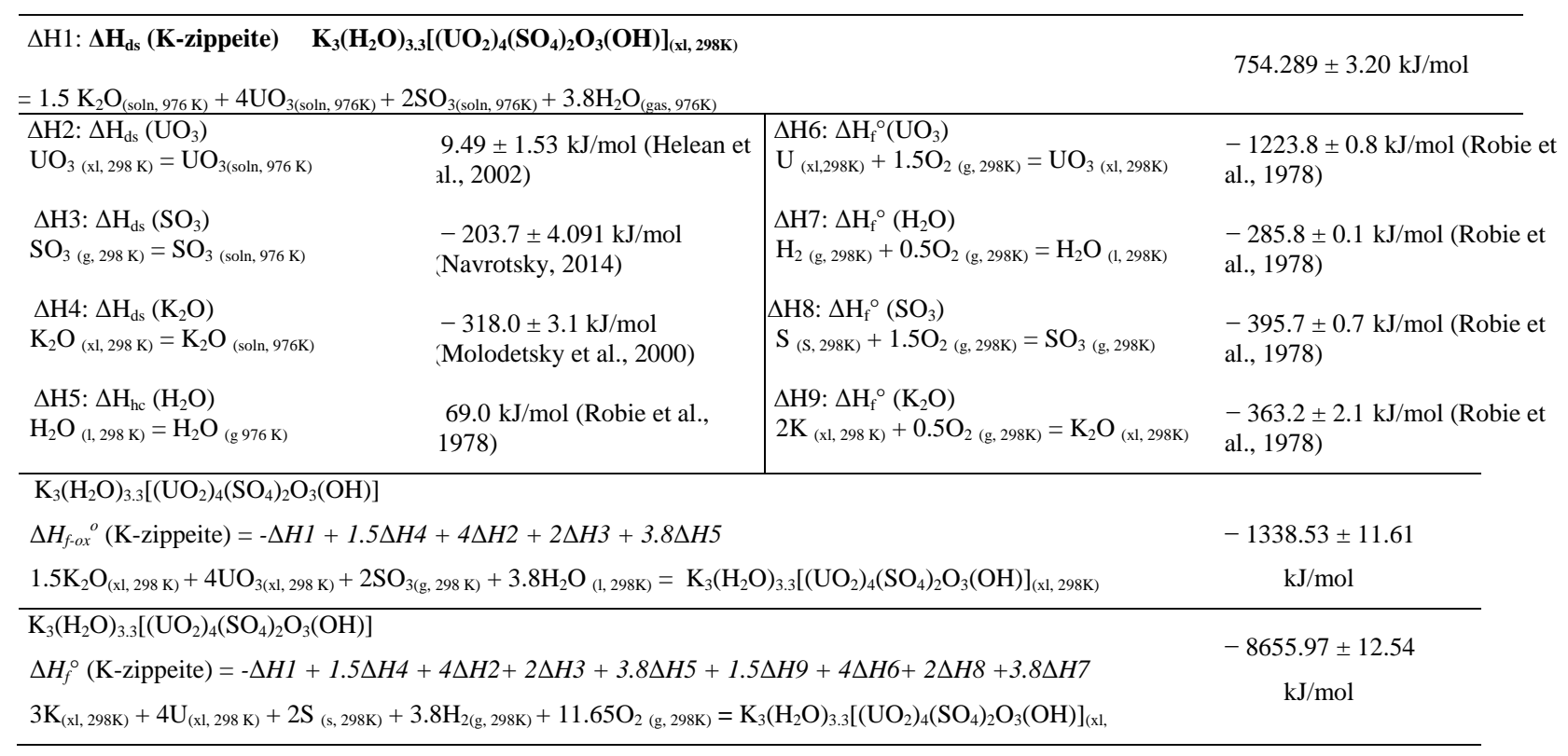


xl, solid material; g, gaseous; soln ,solution; and l, liquid. Error is represented as two standard deviations of the mean.

Solubility experiments were conducted both from undersaturation and supersaturation to constrain the equilibrium state. Measurements of dissolved U, S, and $\mathrm{K}$ in the experimental samples were used to calculate the equilibrium constant and Gibbs free energy of the dissolution reaction (3) as well as the standard-state Gibbs free energy of formation of zippeite. The dissolution reaction of zippeite can be expressed as:

$7 \mathrm{H}^{+}+\mathrm{K}_{3}\left(\mathrm{H}_{2} \mathrm{O}\right)_{3.3}\left[\left(\mathrm{UO}_{2}\right)_{4}\left(\mathrm{SO}_{4}\right)_{2} \mathrm{O}_{3}(\mathrm{OH})\right]=3 \mathrm{~K}^{+}+4 \mathrm{UO}_{2}{ }^{2+}+2 \mathrm{SO}_{4}{ }^{2-}+7.3 \mathrm{H}_{2} \mathrm{O}$

The standard state for zippeite and water are assumed to be the pure phases at the pressure and temperature of interest; the standard state for aqueous species is assumed to be a hypothetical one molal solution at the pressure and temperature of interest that behaves as if infinitely dilute (Gorman-Lewis et al., 2008). Using these standard states, the solubility product of zippeite can be expressed as:

$\mathrm{K}_{\mathrm{sp}}=\frac{a_{K+}^{3} * a_{U O_{2}^{2+}}^{4} * a_{S O_{4}^{2-}}^{2}}{a_{H}^{7}+}$

where ' $a$ ' represents the aqueous activity of the subscripted species. All experiments reached steady-state within two weeks with the highest concentration of dissolved U, S, and K observed in the $\mathrm{pH} 2.8$ experiment, Figure 1. The average concentration of dissolved $\mathrm{U}, \mathrm{S}$, and $\mathrm{K}$ for data points after 15 days of the start of each experiment were used in the calculations of the solubility product. All experiments yielded almost identical extents of non-stoichiometric dissolution, with $\mathrm{K}$ slightly in excess of $\mathrm{U}$ relative to stoichiometric dissolution, and $\mathrm{S}$ slightly lower in concentration relative to $\mathrm{U}$. The $\mathrm{pH} 3.5$ experiments from under- and super-saturation yielded steady-state concentrations of the dissolved elements that were not significantly different from each other, suggesting that equilibrium was reached within the experimental time period. Powder X-ray diffraction patterns of the solid phase residues from the experiment did not reveal any additional crystalline phases and Raman spectra of the residues matched those of the starting material (Figure S4). These observations indicate that a secondary precipitating phase, if present, was minor (less than 5\%) or had the same vibrational modes as the crystalline starting material. 

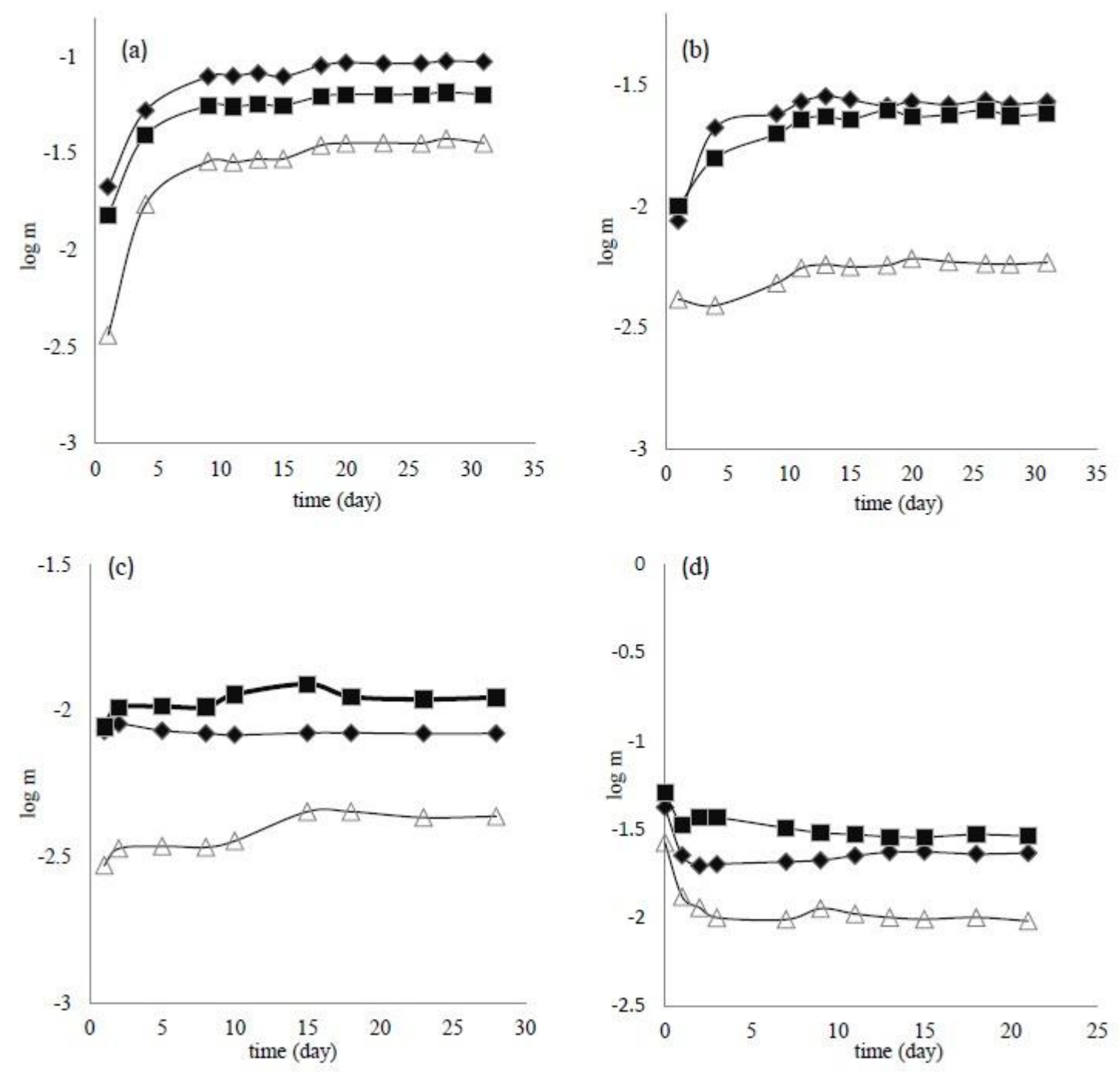

Figure 1. Plot of experimental measurements of the solubility of zippeite in terms of dissolved U (diamonds), K (squares), and S (triangles) as a function of time from undersaturation at pH 2.8 (a), pH 3.5 (b), and pH 4 (c), and from supersaturation at $\mathrm{pH} 3.5$ (d).

The elemental analyses of the experimental samples yielded total elemental concentrations of each solution, but in order to calculate the value of the solubility product, the activities of individual $\mathrm{U}, \mathrm{S}$, and $\mathrm{K}$ species in solution must be determined. We used the aqueous complexation reactions listed in Table S2 (Table S2) in conjunction with FITEQL 2.0 (Herbelin and Westall, 1999) to calculate the activity of each dissolved species in each experimental sample. The Davies equation was used within FITEQL 2.0 to calculate activity coefficients for the ionic species. The calculated value of the $\mathrm{K}_{\mathrm{sp}}$ did not vary consistently with $\mathrm{pH}$. The calculated logarithm of the solubility product averaged for the four different solubility experiments with its $1 \delta$ error is $4.12 \pm 0.11$. This average solubility product value was used to 
determine the standard state Gibbs free energy of the dissolution reaction using the following equation:

$\Delta \mathrm{G}_{\text {reaction }}^{\circ}=-\mathrm{RT}_{\ln \mathrm{K}_{\mathrm{sp}}}^{\circ}$

where $\mathrm{T}$ is the absolute temperature and $\mathrm{R}$ is the gas constant. The $\Delta \mathrm{G}^{\circ}$ reaction value with its $1 \delta$ error was calculated to be $-23.68 \pm 0.65 \mathrm{~kJ} / \mathrm{mol}$. Using literature values for standard state Gibbs free energies of formation $\left(\Delta \mathrm{G}_{\mathrm{f}}^{\circ}\right)$ for each component in the dissolution reaction(Cox et al., 1989; Robie et al., 1978), and the calculated value of $\Delta \mathrm{G}^{\circ}$ reaction, we calculated the standard-state Gibbs free energy of formation of zippeite to be, $-7783.57 \pm 6.90 \mathrm{~kJ} / \mathrm{mol}$ :

$$
\Delta \mathrm{G}_{\mathrm{f}}^{\circ}(\text { Zippeite })=-\Delta \mathrm{G}_{\text {reaction }}^{\circ}-7 \Delta \mathrm{G}_{\mathrm{f} \mathrm{H}+}^{\circ}+3 \Delta \mathrm{G}_{\mathrm{f} \mathrm{K+}}^{\circ}+4 \Delta \mathrm{G}_{\mathrm{f} \mathrm{UO}+2}^{\circ}+2 \Delta \mathrm{G}_{\mathrm{f} \mathrm{SO} 42-}^{\circ}+3.3 \Delta \mathrm{G}_{\mathrm{f}}^{\circ}
$$

$\mathrm{H} 2 \mathrm{O}$

The standard-state Gibbs free energy of formation of zippeite, in conjunction with the standard enthalpy of formation of zippeite from the calorimetry experiments, was used to obtain the standard entropy of formation of zippeite from the following relationship:

$\Delta \mathrm{G}_{\mathrm{f}}^{\circ}=\Delta \mathrm{H}_{\mathrm{f}}^{\circ}-\mathrm{T} \Delta \mathrm{S}_{\mathrm{f}}^{\circ}$

We calculated the value of $\Delta \mathrm{S}_{\mathrm{f}}^{\circ}$ for zippeite with propagated $1 \delta$ error to be $-2926.04 \pm 45.68$ $\mathrm{J} / \mathrm{mol}$.

Zippeite can form as an alteration product of uraninite, and in some cases, it has been found associated with (meta)schoepite in uranium mines (De Vivo et al., 1984). Reaction 8 describes the formation of zippeite from metaschoepite:

$4 \mathrm{UO}_{3} \cdot 2 \mathrm{H}_{2} \mathrm{O}+3 \mathrm{~K}^{+}+2 \mathrm{SO}_{4}{ }^{2-}+\mathrm{H}^{+}=\mathrm{K}_{3}\left(\mathrm{H}_{2} \mathrm{O}\right)_{3.3}\left[\left(\mathrm{UO}_{2}\right)_{4}\left(\mathrm{SO}_{4}\right)_{2} \mathrm{O}_{3}(\mathrm{OH})\right]+4.7 \mathrm{H}_{2} \mathrm{O}$

The calculated value of Gibbs free energy of formation for zippeite from this study was used in order to determine the $\Delta \mathrm{G}^{\circ}{ }_{\mathrm{rxn}}$ for reaction $8(-32.47 \pm 16.33 \mathrm{~kJ} / \mathrm{mol})$. As described by Equation 9, alteration of metaschoepite is dependent on the concentration of the cations in the system:

$\Delta \mathrm{G}_{\mathrm{rxn}}=\Delta \mathrm{G}_{\mathrm{rxn}}^{\circ}+\mathrm{RT} \ln \left(\frac{1}{a_{K+}^{3} * a_{S O_{4}^{2-}}^{2} * a_{H^{+}}}\right)$

For example, for an aqueous sulfate concentration of $11.75 \times 10^{-3} \mathrm{~mol} / \mathrm{L}$, as reported for the post-mining ground water around the Crow Butte uranium mine (Davis and Curtis, 2007), an activity-activity diagram can be calculated, Figure 2. As shown in Figure 2, zippeite is stable at lower $\mathrm{pH}$ and in the presence of high concentrations of $\mathrm{K}^{+}$. For instance, at $\mathrm{pH} 3$, metaschoepite 
is unstable relative to zippeite for any concentration of dissolved potassium approximately above $1 \mathrm{~mol} / \mathrm{L}$.

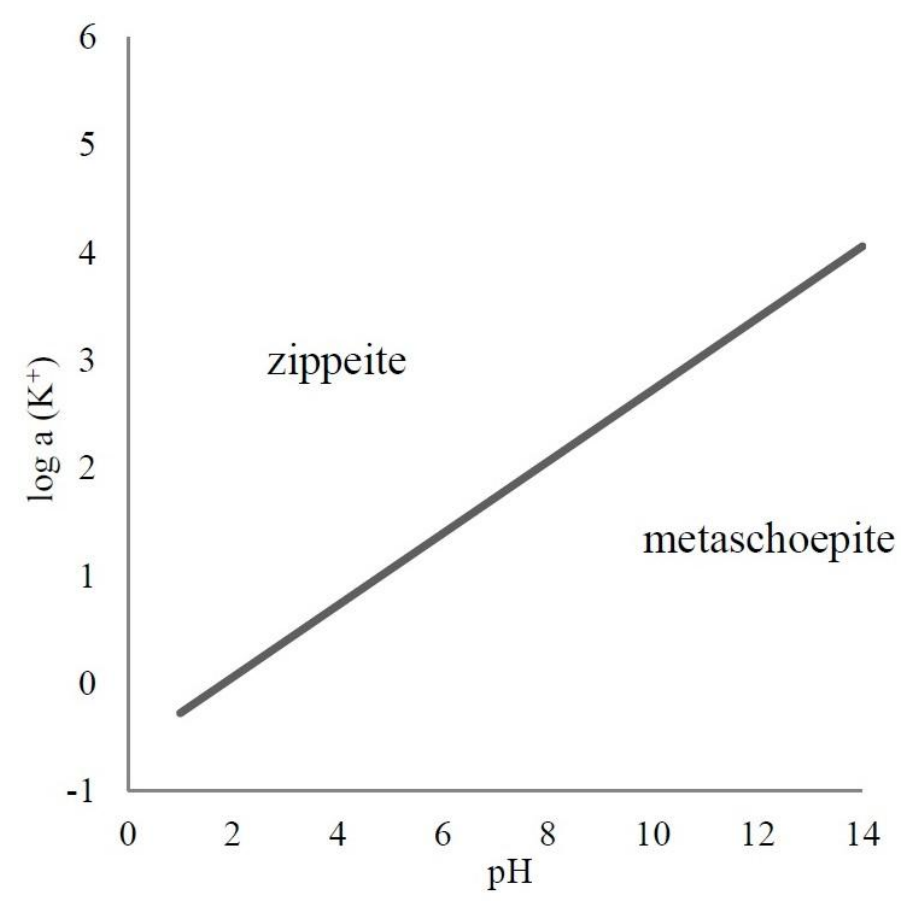

Figure 2. $\mathrm{pH}-\log$ a $\left(\mathrm{K}^{+}\right)$diagram for the system metaschoepite- zippeite at sulfate concentration of $11.75 \times 10^{-3}$ with activity coefficients calculated using an extended Debye-Hückel equation.

In another example, we can use the results from this study to calculate whether zippeite or other uranyl phases in Hanford tanks are the more stable phase within the tanks and in groundwaters at the site. Uranyl oxides and oxyhydrates such as compreignacite and clarkeite have been found in contaminated sediments (Um et al., 2009) around the Hanford site and have been reported as potential uranium-bearing phases present in Hanford tank residual waste. The thermodynamics of the formation of zippeite from $\mathrm{UO}_{3}, \mathrm{Na}$-compreignacite $\left(\mathrm{Na}_{2}\left(\mathrm{UO}_{2}\right)_{6} \mathrm{O}_{4}(\mathrm{OH})_{6}\left(\mathrm{H}_{2} \mathrm{O}\right)_{7}\right)$, and clarkeite $\left(\mathrm{Na}\left(\mathrm{UO}_{2}\right) \mathrm{O}(\mathrm{OH})\right)$ are shown in Table 2. Zippeite is stable only with respect to $\mathrm{UO}_{3}$ for $\mathrm{pH}$ below 3 .

Table2. Zippeite formation from $\mathrm{UO}_{3}$, compreignacite, and clarkeite.

\begin{tabular}{|c|c|c|}
\hline Reactions & $\Delta \mathrm{G}_{\text {reaction }}^{\circ}(\mathrm{kJ} / \mathrm{mol})$ & $\Delta \mathrm{G}_{\mathrm{rxn}}$ at Hanford \\
\hline $4 \mathrm{UO}_{3}+3 \mathrm{~K}^{+}+2 \mathrm{SO}_{4}^{2-}+\mathrm{H}^{+}+3.3 \mathrm{H}_{2} \mathrm{O}=\mathrm{K}_{3}\left(\mathrm{H}_{2} \mathrm{O}\right)_{3.3}\left[\left(\mathrm{UO}_{2}\right)_{4}\left(\mathrm{SO}_{4}\right)_{2} \mathrm{O}_{3}(\mathrm{OH})\right]$ & $-78.30 \pm 7.17$ & $\begin{array}{c}<0 \\
\text { For pH below } 3\end{array}$ \\
\hline $\begin{array}{l}2\left(\mathrm{Na}_{2}\left(\mathrm{UO}_{2}\right)_{6} \mathrm{O}_{4}(\mathrm{OH})_{6}\left(\mathrm{H}_{2} \mathrm{O}\right)_{7}\right)+7 \mathrm{H}^{+}+9 \mathrm{~K}^{+}+6 \mathrm{SO}_{4}{ }^{2-}= \\
3\left(\mathrm{~K}_{3}\left(\mathrm{H}_{2} \mathrm{O}\right)_{3.3}\left[\left(\mathrm{UO}_{2}\right)_{4}\left(\mathrm{SO}_{4}\right) 2 \mathrm{O}_{3}(\mathrm{OH})\right]\right)+4 \mathrm{Na}^{+}+12.1 \mathrm{H}_{2} \mathrm{O}\end{array}$ & $-165.93 \pm 32.06$ & $\begin{array}{l}>0 \\
\text { For all } \mathrm{pH}\end{array}$ \\
\hline $\begin{array}{l}4\left(\mathrm{Na}\left(\mathrm{UO}_{2}\right) \mathrm{O}(\mathrm{OH})\right)+3 \mathrm{~K}^{+}+2 \mathrm{SO}_{4}{ }^{2-}+5 \mathrm{H}^{+}=\mathrm{K}_{3}\left(\mathrm{H}_{2} \mathrm{O}\right)_{3.3}\left[\left(\mathrm{UO}_{2}\right)_{4}\left(\mathrm{SO}_{4}\right)_{2} \mathrm{O}_{3}(\mathrm{OH})\right]+ \\
4 \mathrm{Na}^{+}+0.7 \mathrm{H}_{2} \mathrm{O}\end{array}$ & $+33522.095 \pm 49.48$ & $\begin{array}{l}\quad>0 \\
\text { For all } \mathrm{pH}\end{array}$ \\
\hline
\end{tabular}


Calculations are based on the reported composition of a Hanford tank solution with the following composition: $\mathrm{UO}_{2}{ }^{2+}$ concentration of $2.6 \times 10^{-5} \mathrm{~mol} / \mathrm{L}, \mathrm{K}^{+}$concentration of $7.33 \times 10^{-3} \mathrm{~mol} / \mathrm{L}$, and $\mathrm{SO}_{4}{ }^{2-}$ concentration of $1.38 \times 10^{-2} \mathrm{~mol} / \mathrm{L}$ (Um et al., 2009). $\Delta \mathrm{G}_{\mathrm{rxn}}=\Delta \mathrm{G}_{\mathrm{rxn}}^{\circ}+\mathrm{RT} \ln (Q)$, in which $\mathrm{Q}$ is the reaction quotient. Error is represented as one standard deviation

Zippeite can form from ions in solution when there is significant evaporation to increase the concentration of $\mathrm{UO}_{2}{ }^{2+}, \mathrm{SO}_{4}{ }^{2-}$, and $\mathrm{K}^{+}$(Finch and Murakami, 1999). Using our calculated solubility product for zippeite, we calculated that Hanford tank wastes are supersaturated with respect to zippeite for any $\mathrm{pH}$ above 5 based on the activities of $\mathrm{UO}_{2}{ }^{+2}, \mathrm{~K}^{+}$, and $\mathrm{SO}_{4}{ }^{2-}$ at the Hanford site. Since the pH of the tanks is above 4 (Um et al., 2009), our calculations suggest that zippeite can form directly from precipitation from Hanford tank waste solutions. The reason not been found outside of the tanks is likely that uranyl oxyhydrates and other less soluble minerals such as phosphates have formed (Um et al., 2009) and that the concentrations of dissolved $\mathrm{UO}_{2}{ }^{2+}$, sulfate, and $\mathrm{K}^{+}$, are lower in the groundwater beneath the tanks than in the tank solutions and hence are below the saturation state for zippeite.

ACKNOWLEDGEMENTS. This work was funded by the Office of Basic Energy Sciences of the U.S. Department of Energy as part of the Materials Science of Actinides Energy Frontiers Research Center (DESC0001089). Powder X-Ray Diffraction, Raman spectroscopy and calorimetric analyses were done at the Materials Characterization Facility (MCF) as part of the Center for Sustainable Energy at Notre Dame. ICP-OES analysis was conducted at the Center for Environmental Science and Technology (CEST) at Notre Dame.

\section{References}

Brugger, J., Burns, P.C., Meisser, N., 2003. Contribution to the mineralogy of acid drainage of Uranium minerals: Marecottite and the zippeite-group. American Mineralogist, 88(4): 676-685.

Burns, P.C., Deely, K.M., Hayden, L.A., 2003. The crystal chemistry of the zippeite group. The Canadian Mineralogist, 41(3): 687-706.

Chen, F., Ewing, R.C., Clark, S.B., 1999. The Gibbs free energies and enthalpies of formation of U6+ phases: An empirical method of prediction. American Mineralogist, 84(4): 650-664.

Choppin, G., Mathur, J., 1991. Hydrolysis of actinyl (VI) cations. Radiochimca Acta, 52(1): 25-28.

Cox, J., Wagman, D.D., Medvedev, V.A., 1989. CODATA key values for thermodynamics. Chem/Mats$\mathrm{SCI} / \mathrm{E}$.

Davis, J., Curtis, G.P., 2007. Consideration of geochemical issues in groundwater restoration at uranium in-situ leach mining facilities. Division of Fuel, Engineering, and Radiological Research, Office of Nuclear Regulatory Research, US Nuclear Regulatory Commission. 
De Vivo, B., Ippolito, F., Capaldi, G., Simpson, P., 1984. Uranium geochemistry, mineralogy, geology, exploration and resources. Springer.

Finch, R., Murakami, T., 1999. Systematics and paragenesis of uranium minerals. Reviews in Mineralogy, 38: 91-180.

Frondel, C., Ito, J., Honea, R.M., Weeks, A.M., 1976. Mineralogy of the zippeite group. Canadian Mineralogist, 14(4): 429-436.

Gorman-Lewis, D., Burns, P.C., Fein, J.B., 2008. Review of uranyl mineral solubility measurements. The Journal of Chemical Thermodynamics, 40(3): 335-352.

Guillaumont, R. et al., 2003. Update on the Chemical Thermodynamics of Uranium, Neptunium, and Plutonium. Elsevier, Amsterdam, 919 pp.

Helean, K. et al., 2002. Enthalpies of formation of Ce-pyrochlore, Ca 0.93 Ce 1.00 Ti 2.035 O 7.00, Upyrochlore, Ca $1.46 \cup 4+0.23 \cup 6+0.46 \mathrm{Ti} 1.8507 .00$ and Gd-pyrochlore, Gd 2 Ti 2 O 7: three materials relevant to the proposed waste form for excess weapons plutonium. Journal of nuclear materials, 303(2): 226-239.

Herbelin, A.L., Westall, J.C., 1999. FITEQL: A computer program for determination of chemical equilibrium constants from experimental data. Version, 4: 99-01.

Martell, A.E., Smith, R.M., Motekaitis, R., 2004. NIST critically selected stability constants of metal complexes. NIST standard reference database, 46(6.0).

Meinrath, G., Lis, S., Piskuła, Z., Glatty, Z., 2006. An application of the total measurement uncertainty budget concept to the thermodynamic data of uranyl (VI) complexation by sulfate. The Journal of Chemical Thermodynamics, 38(11): 1274-1284.

Merkel, B., Planer-Friedrich, B., Wolkersdorfer, C., 2002. Uranium in the Aquatic Environment: proceedings of the International Conference [on] Uranium Mining and Hydrogeology III and the International Mine Water Association Symposium, Freiberg, Germany, 15-21 September 2002: with 453 figures, 151 tables and a CD-ROM. Springer Science \& Business Media.

Molodetsky, I., Navrotsky, A., DiSalvo, F., Lerch, M., 2000. Energetics of oxidation of oxynitrides: Zr-N-O, $\mathrm{Y}-\mathrm{Zr}-\mathrm{N}-\mathrm{O}, \mathrm{Ca}-\mathrm{Zr}-\mathrm{N}-\mathrm{O}$, and $\mathrm{Mg}-\mathrm{Zr}-\mathrm{N}-\mathrm{O}$. Journal of Materials Research, 15(11): 2558-2570.

Navrotsky, A., 1977. Progress and new directions in high temperature calorimetry. Physics and Chemistry of Minerals, 2(1-2): 89-104.

Navrotsky, A., 1997. Progress and new directions in high temperature calorimetry revisited. Physics and Chemistry of Minerals, 24(3): 222-241.

Navrotsky, A., 2014. Progress and New Directions in Calorimetry: A 2014 Perspective. Journal of the American Ceramic Society, 97(11): 3349-3359.

O'Brien, T., Williams, P., 1981. The aqueous chemistry of uranium minerals. Part 3. Monovalent cation zippeites. Inorganic and Nuclear Chemistry Letters, 17(3): 105-107.

Plášil, J., Dušek, M., Čejka, J., Sejkora, J., 2014a. The crystal structure of rabejacite, the Ca2+-dominant member of the zippeite group. Mineralogical Magazine, 78(5): 1249-1264.

Plášil, J. et al., 2011a. Sejkoraite-(Y), a new member of the zippeite group containing trivalent cations from Jáchymov (St. Joachimsthal), Czech Republic: description and crystal structure refinement. American Mineralogist, 96(7): 983-991.

Plášil, J. et al., 2013. Meisserite, $\mathrm{Na5}$ (UO2)(SO4) 3 (SO3OH)(H2O), a new uranyl sulfate mineral from the Blue Lizard mine, San Juan County, Utah, USA. Mineralogical Magazine, 77(7): 2975-2988.

Plášil, J., Kampf, A.R., Kasatkin, A.V., Marty, J., 2014b. Bluelizardite, Na7 (UO2)(SO4) 4Cl (H2O) 2, a new uranyl sulfate mineral from the Blue Lizard mine, San Juan County, Utah, USA. Journal of Geosciences, 59(2): 145-158.

Plášil, J. et al., 2011b. The crystal structure of natural zippeite, K1. 85H+ 0.15 [(UO2) 402 (SO4) 2 (OH) 2](H2O) 4, from Jáchymov, Czech Republic. The Canadian Mineralogist, 49(4): 1089-1103. 
Plášil, J., Sejkora, J., Škoda, R., Škácha, P., 2014c. The recent weathering of uraninite from the Červená vein, Jáchymov (Czech Republic): a fingerprint of the primary mineralization geochemistry onto the alteration association. Journal of Geosciences, 59(3).

Robie, R.A., Hemingway, B.S., Fisher, J.R., 1978. Thermodynamic properties of minerals and related substances at 298. $15 \mathrm{~K}$ and 1 bar (10/sup 5/pascals) pressure and at higher temperatures, Geological Survey, Washington, DC (USA).

Ryan, M.P., Williams, D.E., Chater, R.J., Hutton, B.M., McPhail, D.S., 2002. Why stainless steel corrodes. Nature, 415(6873): 770-774.

Tingey, J.M., Bryan, G.H., DesChane, J.R., 2004. Dangerous Waste Characteristics of Waste from Hanford Tank 241-S-109. Pacific Northwest National Laboratory.

Tripathi, V., 1983. Uranium transport modeling: geochemical data and sub-models Ph. D, thesis, Stanford University, Stanford, CA, USA.

Um, W. et al., 2009. Uranium phases in contaminated sediments below Hanford's U tank farm. Environmental science \& technology, 43(12): 4280-4286.

Williams, D.E., Zhu, Y.Y., 2000. Explanation for initiation of pitting corrosion of stainless steels at sulfide inclusions. Journal of the Electrochemical Society, 147(5): 1763-1766. 


\section{Supporting Information:}

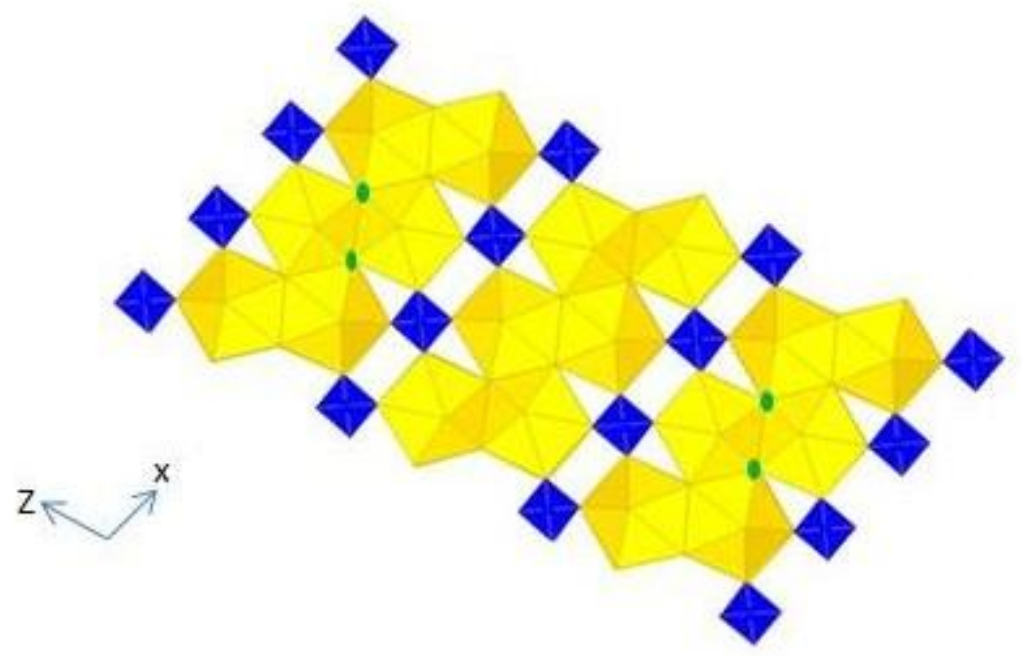

Figure S1. The sheet of uranyl and sulfate polyhedra in the zippeite structure. Uranyl pentagonal bipyramids are shown in yellow and sulfate tetraheda are shown in blue. Green circles correspond to the hydroxyl groups (Burns et al., 2003).

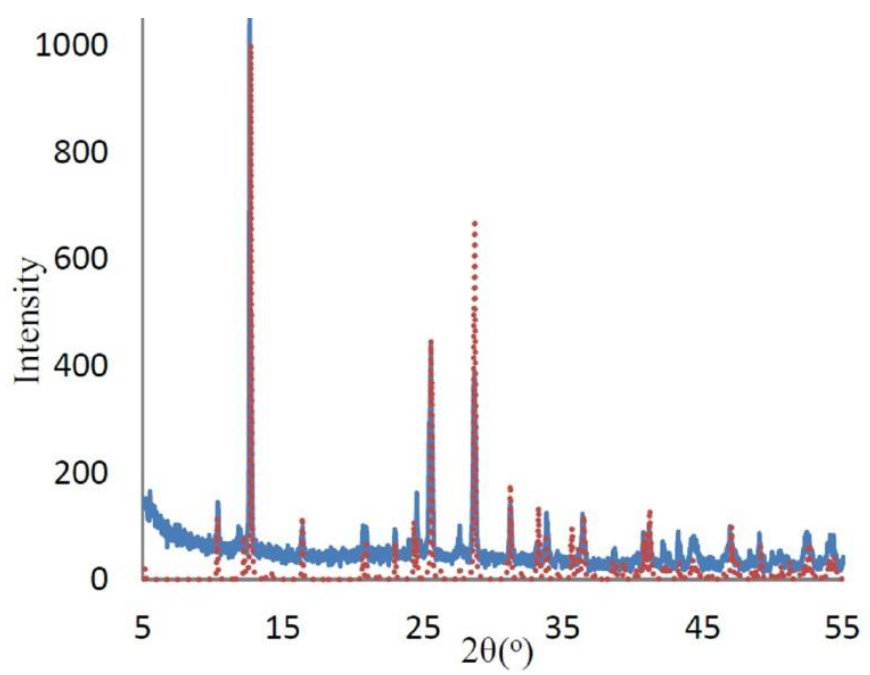

Figure S2. Zippeite PXRD pattern. Blue trace corresponds to synthetic zippeite, and red peaks correspond to peak positions and heights calculated from the structural model (Burns et al., 2003). 


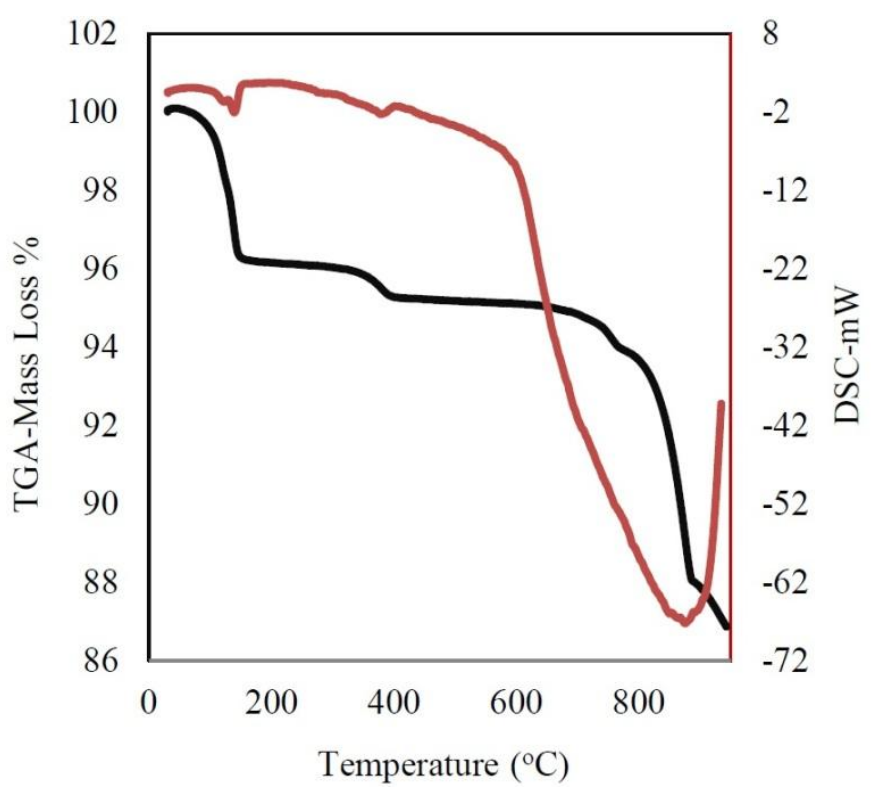

Figure S3. DSC-TGA curve for synthetic K-zippeite.

Table S1. Chemical compositions of synthetic zippeite obtained from ICP-OES analysis

\begin{tabular}{c|c|c|c} 
Sample & Ratio & Ideal (Burns et al., 2003) & Actual \\
\hline \multirow{2}{*}{ K-zippite } & mol K/mol U & 0.75 & $0.72 \pm 0.3$ \\
\cline { 2 - 4 } & mol S/mol U & 0.5 & $0.49 \pm 0.02$ \\
\hline
\end{tabular}

The error is stated as two standard deviations of the mean. 


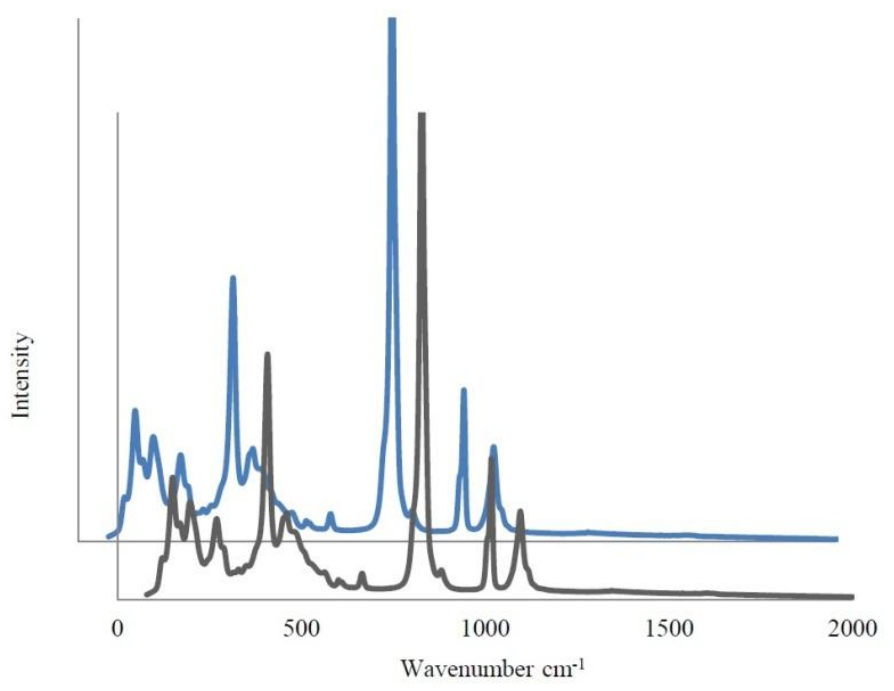

Figure S4. Raman spectrum of zippeite. Black represents the spectra of the starting material for solubility experiments and blue corresponds to the spectrum of the residue of solubility experiments. The Raman spectrum of the solubility experiment residue is slightly shifted for clarity.

Table S2. Aqueous complexation reactions

Reactions $\log \mathrm{K}$

(Reference)
$\mathrm{UO}_{2}{ }^{2+}+\mathrm{H}_{2} \mathrm{O}=\mathrm{UO}_{2} \mathrm{OH}^{+}+\mathrm{H}^{+}$
$-5.25$
(Guillaumont et al., 2003)
$\mathrm{UO}_{2}{ }^{2+}+2 \mathrm{H}_{2} \mathrm{O}=\mathrm{UO}_{2}(\mathrm{OH})_{2}{ }^{\circ}+2 \mathrm{H}^{+}$
$-12.15$
(Guillaumont et al., 2003)
$\mathrm{UO}_{2}{ }^{2+}+3 \mathrm{H}_{2} \mathrm{O}=\mathrm{UO}_{2}(\mathrm{OH})_{3}{ }^{-}+3 \mathrm{H}^{+}$
$-20.25$
(Guillaumont et al., 2003)
$\mathrm{UO}_{2}{ }^{2+}+4 \mathrm{H}_{2} \mathrm{O}=\mathrm{UO}_{2}(\mathrm{OH})_{4}{ }^{2-}+4 \mathrm{H}^{+}$
$-32.4$
(Guillaumont et al., 2003)
$2 \mathrm{UO}_{2}{ }^{2+}+\mathrm{H}_{2} \mathrm{O}=\left(\mathrm{UO}_{2}\right)_{2} \mathrm{OH}^{3+}+\mathrm{H}^{+}$
$-2.70$
(Guillaumont et al., 2003)
$2 \mathrm{UO}_{2}{ }^{2+}+2 \mathrm{H}_{2} \mathrm{O}=\left(\mathrm{UO}_{2}\right)_{2}(\mathrm{OH})_{2}{ }^{2+}+2 \mathrm{H}^{+}$
$-5.62$
(Guillaumont et al., 2003)
$3 \mathrm{UO}_{2}{ }^{2+}+5 \mathrm{H}_{2} \mathrm{O}=\left(\mathrm{UO}_{2}\right)_{3}(\mathrm{OH})_{5}{ }^{+}+5 \mathrm{H}^{+}$
$-15.55$
(Guillaumont et al., 2003)
$3 \mathrm{UO}_{2}{ }^{2+}+7 \mathrm{H}_{2} \mathrm{O}=\left(\mathrm{UO}_{2}\right)_{3}(\mathrm{OH})_{7}{ }^{-}+7 \mathrm{H}^{+}$
$-32.20$
(Guillaumont et al., 2003)
$4 \mathrm{UO}_{2}{ }^{2+}+7 \mathrm{H}_{2} \mathrm{O}=\left(\mathrm{UO}_{2}\right)_{4}(\mathrm{OH})_{7}{ }^{+}+7 \mathrm{H}^{+}$
$-21.90$
(Guillaumont et al., 2003)
$\mathrm{UO}_{2}{ }^{2+}+\mathrm{CO}_{3}{ }^{2-}=\mathrm{UO}_{2} \mathrm{CO}_{3}$
9.94
(Guillaumont et al., 2003)
$\mathrm{UO}_{2}{ }^{2+}+2 \mathrm{CO}_{3}{ }^{2-}=\mathrm{UO}_{2}\left(\mathrm{CO}_{3}\right)_{2}{ }^{2-}$
16.61
(Guillaumont et al., 2003)
$\mathrm{UO}_{2}{ }^{2+}+3 \mathrm{CO}_{3}{ }^{2-}=\mathrm{UO}_{2}\left(\mathrm{CO}_{3}\right)_{3}{ }^{4-}$
21.84
(Guillaumont et al., 2003)
$3 \mathrm{UO}_{2}{ }^{2+}+6 \mathrm{CO}_{3}{ }^{2-}=\left(\mathrm{UO}_{2}\right)_{3}\left(\mathrm{CO}_{3}\right)_{6}{ }^{6-}$
$54.00 \quad$ (Guillaumont et al., 2003) 


\begin{tabular}{|c|c|c|}
\hline $2 \mathrm{UO}_{2}{ }^{2+}+\mathrm{CO}_{3}{ }^{2-}+3 \mathrm{H}_{2} \mathrm{O}=\left(\mathrm{UO}_{2}\right)_{2} \mathrm{CO}_{3}(\mathrm{OH})_{3}{ }^{-}+3 \mathrm{H}^{+}$ & -0.86 & (Guillaumont et al., 2003) \\
\hline $3 \mathrm{UO}_{2}^{2+}+\mathrm{CO}_{3}^{2-}+3 \mathrm{H}_{2} \mathrm{O}=\left(\mathrm{UO}_{2}\right)_{3} \mathrm{O}(\mathrm{OH})_{2}\left(\mathrm{HCO}_{3}\right)^{+}+3 \mathrm{H}^{+}$ & 0.65 & (Guillaumont et al., 2003) \\
\hline $11 \mathrm{UO}_{2}{ }^{2+}+6 \mathrm{CO}_{3}{ }^{2-}+12 \mathrm{H}_{2} \mathrm{O}=\left(\mathrm{UO}_{2}\right)_{11}\left(\mathrm{CO}_{3}\right)_{6}(\mathrm{OH})_{12}{ }^{2-}+12 \mathrm{H}^{+}$ & 36.40 & (Guillaumont et al., 2003) \\
\hline $\mathrm{UO}_{2}^{2+}+\mathrm{SO}_{4}^{2-}=\mathrm{UO}_{2} \mathrm{SO}_{4}$ & 3.150 & (Guillaumont et al., 2003) \\
\hline $\mathrm{UO}_{2}^{2+}+2 \mathrm{SO}_{4}{ }^{2-}=\mathrm{UO}_{2}(\mathrm{SO} 4)_{2}^{2-}$ & 4.140 & (Guillaumont et al., 2003) \\
\hline $\mathrm{UO}_{2}{ }^{2+}+3 \mathrm{SO}_{4}{ }^{2-}=\mathrm{UO}_{2}(\mathrm{SO} 4)_{3}{ }^{4-}$ & 3.020 & (Guillaumont et al., 2003) \\
\hline $\mathrm{UO}_{2}^{2+}+\mathrm{HSO}_{4}^{-}=\mathrm{UO}_{2}(\mathrm{HSO} 4)^{+}$ & 2.95 & (Martell et al., 2004) \\
\hline $\mathrm{H}^{+}+\mathrm{SO}_{4}^{2-}=\mathrm{HSO}_{4}^{-}$ & 1.980 & (Guillaumont et al., 2003) \\
\hline $\mathrm{K}^{+}+\mathrm{OH}^{-}=\mathrm{KOH}_{(\mathrm{aq})}$ & -14.46 & (Martell et al., 2004) \\
\hline $\mathrm{K}^{+}+\mathrm{HSO}_{4}^{-}=\mathrm{KHSO}_{4}$ & 0.85 & (Martell et al., 2004) \\
\hline $\mathrm{K}^{+}+\mathrm{ClO}_{4}^{-}=\mathrm{KClO}_{4}$ & -0.01 & (Martell et al., 2004) \\
\hline $\mathrm{Na}^{+}+\mathrm{CO}_{3}{ }^{2-}=\mathrm{NaCO}_{3}^{-}$ & -1.27 & (Martell et al., 2004) \\
\hline $\mathrm{Na}^{+}+\mathrm{CO}_{3}^{2-}+\mathrm{H}^{+}=\mathrm{NaHCO}_{3(\mathrm{aq})}$ & -10.03 & (Martell et al., 2004) \\
\hline $\mathrm{Na}^{+}+\mathrm{OH}^{-}=\mathrm{NaOH}_{(\mathrm{aq})}$ & -14.18 & (Martell et al., 2004) \\
\hline $\mathrm{Na}^{+}+\mathrm{CO}_{3}{ }^{2-}+\mathrm{H}^{+}=\mathrm{NaHCO}_{3(\mathrm{aq})}$ & -10.03 & (Martell et al., 2004) \\
\hline
\end{tabular}

